Article

\title{
Gold Nanostar Colorimetric Detection of Fructosyl Valine as a Potential Future Point of Care Biosensor Candidate for Glycated Haemoglobin Detection
}

\author{
Danielle Wingrove Mulder*, Masauso Moses Phiri ${ }^{\circledR}$ and Barend Christiaan Vorster(] \\ Center for Human Metabolomics, North-West University, Hoffman street, Potchefstroom 2520, South Africa \\ * Correspondence: danitedder@gmail.com
}

Received: 27 May 2019; Accepted: 7 August 2019; Published: 14 August 2019

\begin{abstract}
Diabetes Mellitus is a growing global concern. The current methods used to detect glycated haemoglobin are precise, however, utilise expensive equipment, reagents and consumables. These are luxuries which rural communities cannot access. The nanotechnology methods which have been developed for glycated haemoglobin detection are predominantly electrochemically based, have complicated lengthy fabrication processes and utilise toxic chemicals. Here a fructosyl amino acid oxidase gold nanostar biosensor has been developed as a potential future point of care biosensor candidate for glycated haemoglobin detection. The workup done on this biosensor showed that it was able to give a spectrophotometric readout and colorimetric result with naked eye detection in blank serum spiked with fructosyl valine.
\end{abstract}

Keywords: biosensor; colorimetric; diabetes mellitus; gold nanostars; glycated haemoglobin and hydrogen peroxide

\section{Introduction}

The growing prevalence of Diabetes Mellitus is a global concern and South Africa is no exception [1]. Glycated haemoglobin $\left(\mathrm{HbA}_{1 \mathrm{C}}\right)$ is one of the three confirmatory diagnostic tests for diabetes along with fasting plasma glucose and oral glucose tolerance test $[2,3]$. $\mathrm{HbA}_{1 \mathrm{C}}$ is haemoglobin $\mathrm{HbA}$ that has glucose covalently attached to the $\mathrm{N}$-terminal valine of the beta chain via a nonenzymatic attachment process [4]. $\mathrm{HbA}_{1 \mathrm{C}}$ concentration is dependent on the erythrocyte life span and the glucose concentration of glucose found in the blood, therefore, any condition which influences the 120 day erythrocyte life span will also affect $\mathrm{HbA}_{1 \mathrm{C}}$ [4]. $\mathrm{HbA}_{1 \mathrm{C}}$ is not only used in diabetes diagnosis but is also a recognised risk factor for cardiovascular disease [5,6]. In addition to its diagnostic application $\mathrm{HbA}_{1 \mathrm{C}}$ is used also to monitor glycemic control, evaluate the need for therapy change and predict the development of microvascular complications.

There are more than 150 described methods available for $\mathrm{HbA}_{1 \mathrm{C}}$ determination. Most of these can be classified as high-performance liquid chromatography (HPLC), immunoassays, affinity chromatography, capillary electrophoresis and enzymatic assays [4]. Selection of the most appropriate method given the clinical requirement in a specific setting is a trade-off between specificity given the haemoglobin variants and genetic variation, speed of analysis and skills required, and lastly infrastructure requirement and cost of testing [2,3,7-12]. Currently there are also nanotechnology based assays for $\mathrm{HbA}_{1 \mathrm{C}}$ determination, however, most of these methods utilise electrochemistry which have lengthy complicated fabrication processes, use toxic chemicals and may have glucose interference [13-17].

The enzymatic assay utilises a Bacillus sp. protease in a proteolytic digestion to release glycated valine from haemoglobin beta chains. The glycated valine then serves as a substrate for fructosyl amino 
acid oxidase (FAO) which produces hydrogen peroxide as a product [11]. By using the recombinant fructosyl valine oxidase isolated from Escherichia coli species it was shown that there was no interference from glucose, bilirubin, uric acid, triglycerides etc. as it had an increased specificity for glycated valine $[11,18]$. Detection is then achieved by the addition of horseradish peroxidase and a chromatogen.

The reaction scheme for this reaction is illustrated in Figure 1.
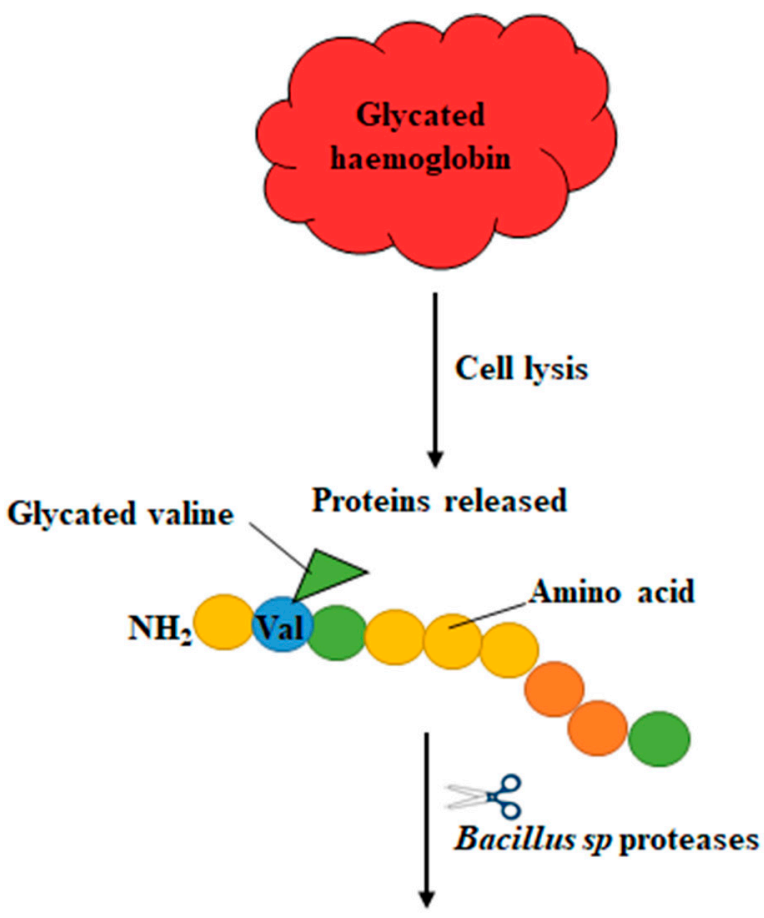

Amino acids released

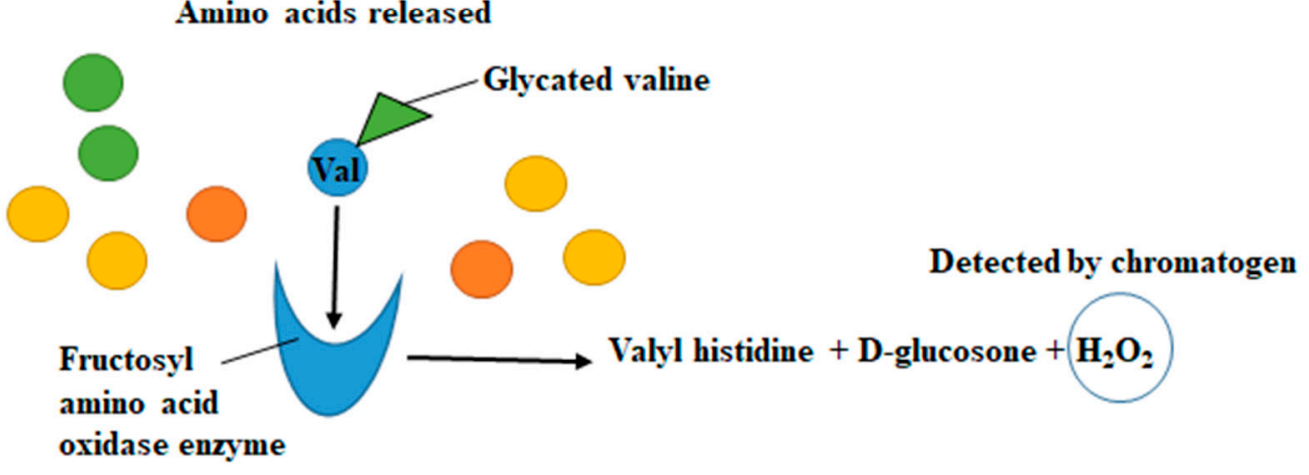

Figure 1. Illustration of the enzyme assay used to measure $\mathrm{HbA}_{1 \mathrm{C}}[11,19]$.

Despite the niftiness of the method the assay, it is expensive which limits widespread implementation and POC testing (Figure 1).

Advances in nanotechnology have resulted in a wide range of nanosensing platforms for POC testing which have unique properties that are revolutionising the medical sector, particularly those comprised of gold nanoparticles [20]. Their easy synthesis method and their unique physical properties is what makes gold nanoparticles useful. This allows for manipulation and design [21]. Functional gold nanoparticles have been successfully used in protein, enzyme, oligonucleotide, metal ions and small molecule detection and can act as both the molecular acceptor as well as the signal transducer enhancing the sensitivity of a sensor [22,23]. As an added benefit functionalising gold nanoparticles with enzymes has been shown to stabilise both the gold nanoparticle and maintain the enzyme performance especially in a complex biological matrix [24,25]. Gold nanostars are particularly useful as biosensor detectors due to the fact that the protruding arms add to the lightning rod effect and plasmonic contributions [26]. 
A change in the absorption spectrum is associated with the gold nanostars surface electrons oscillations. The oscillations are influenced by the gold nanostars size, shape, arm density, surface coating and dielectric environment and can be detected by changes in scattering or absorption spectra or colour variation of the nanoparticle solution [27-30]. In literature it was shown that the localised surface plasmon resonance (LSPR) of gold nanostars shifts in response to silver ions which are reduced on to the nanostars surface in the presence of hydrogen peroxide [31].

The difference between traditional organic dye probe reactions and gold nanoparticle-based colorimetric assays is the low extinction coefficients of organic dyes rendering them less sensitive than the high gold nanoparticle extinction coefficients owed to their LSPRs. This has resulted in the gold nanoparticle-based colorimetric assays having a detection limit in the nanomolar range and in some instances lower [30]. Despite the impressive level of detections and signal amplifications of the nanoparticles they also have their challenges. These challenges include interferences in biological environments, long incubation times as well as complicated fabrication processes [32].

The aim of this research was to develop and adapt the enzymatic $\mathrm{HbA}_{1 \mathrm{C}}$ assay by utilising a gold nanostar biosensor as opposed to a traditional chromatogen. Such a modification will enable smaller sample volumes and quantification based on colour changes which are considered favourable for future POC applications. The results obtained showed functionalised gold nanostars with fructosyl amino acid oxidase to be a good biosensor candidate as it produced a good colorimetric differentiation between different concentrations of fructosyl valine which was detectable by the naked eye and spectrophotometrically.

\section{Materials and Methods}

\subsection{Materials}

All syntheses were done in $5 \mathrm{~mL}$ screw cap tubes (Ascendis Medical, Johannesburg, South Africa). The stoppered polystyrene cuvettes used for dynamic light scattering was purchased from Sigma-Aldrich. The colorimetric assays were carried out in a clear, flat bottomed 96-well plate (Corning, Corning, NY, USA). The chemicals used were purchased from Sigma-Aldrich unless stated otherwise. The chemicals used were; 4-(2-hydroxyethyl)-1-piperazineethanesulfonic acid (HEPES), gold (III) chloride trihydrate, silver nitrate $\left(\mathrm{AgNO}_{3}\right)$, polyvinylpyrrolidone (PVP) 10,000, tris-acetate EDTA buffer (TAE), tris-EDTA buffer (TRIS), sodium hydroxide, sodium chloride, 3,3'-dithiobis(sulfosuccinimidyl propionate) (DTSSP) recombinant fructosyl amino acid oxidase isolated from Escherichia coli species (FAO), fructosyl valine (Industrial Analytical, Johannesburg, South Africa), glucose (Dischem, Cape Town, South Africa) and Medidrug Basis-line S human blank serum (Industrial Analytical, Johannesburg, South Africa).

\subsection{Instrumentation}

All spectra for the research were obtained using a HT Synergy microplate spectrophotometer scanned at 400-800 nm wavelengths and Gen5.1 as the corresponding software (BioTEK). Dynamic light scattering (DLS) was used to estimate the hydrodynamic diameter of the nanostars functionalised with fructosyl amino acid oxidase $[33,34]$. DLS was performed on a Zetasizer Nano (Malvern, Royston, UK) in backscatter mode using Zietasizer version 6.20 software and stoppered polystyrene cuvettes limiting dust contamination. The morphology of the functionalised nanostars were determined with high resolution transmission electron microscopy (HR-TEM) and energy-dispersive X-ray spectroscopy (EDS) on a Tecnai F20 high resolution transmission electron microscope. The samples were prepared by spotting the nanostars on to copper grids and air drying them. The characterisation of the functionalised nanostars were determined in 75\% agarose gel electrophoresis in $1 \times \mathrm{TAE}, 50 \mathrm{~V}$ for $45 \mathrm{~min}$. The samples were prepared by adding $8 \mu \mathrm{L}$ nanostars to $4 \mu \mathrm{L} 50 \%$ glucose solution [35]. 


\subsection{Nanostar (AuNs) Synthesis}

The gold nanostars were synthesised using the HEPES buffer method described and characterised by our laboratory [36]. Briefly, $2 \mathrm{~mL} 100 \mathrm{mM}$ HEPES buffer ( $\mathrm{pH} 7.4$ ) was added to $3 \mathrm{~mL}$ deionised water (Millipore, $18.2 \Omega \mathrm{M}$ ), followed by $20 \mu \mathrm{L} 50 \mathrm{mM}$ gold (III) chloride trihydrate $\left(\mathrm{HAuCl}_{4} \cdot 4 \mathrm{H}_{2} \mathrm{O}\right.$ ) and $4 \mu \mathrm{L} 1 \mathrm{mM}$ silver nitrate. The screw cap tube was mixed by end-to-end tube inversion and left to stand at room temperature for approximately $30 \mathrm{~min}$ until the solution turned a blue colour. The nanostars were then capped with $600 \mu \mathrm{L} 25 \mathrm{mM}$ PVP, the tube was inverted a few times and left to stand at room temperature overnight. The samples were then centrifuged and resuspended in $500 \mu \mathrm{L}$ of deionised water after removal of the supernatant.

\subsection{Fructosyl Amino Acid Oxidase (FAO) Functionalised Nanoparticles (FAO-AuNs)}

The nanostars were synthesised as described above (AuNs synthesis method) with the following modifications that were previously described for functionalisation with glucose oxidase [37]: Once the nanostars were synthesised by the AuNs method. Capping was performed with a PVP solution diluted to $2.5 \mathrm{mM}$ and the incubation time was shortened to $90 \mathrm{~min}$. The suspension was centrifuged at $1990 \times \mathrm{g}$ for $40 \mathrm{~min}$ and the FAO-AuNs were resuspended in $500 \mu \mathrm{L} 100 \mathrm{mM}$ HEPES (pH 6.9) after careful removal of the supernatant. Four replicates of the resuspended nanostars were then pooled to make up $2 \mathrm{~mL}$. $100 \mu \mathrm{L} 0.5 \mathrm{mM}$ freshly made up DTSSP was added to the $2 \mathrm{~mL}$ stars, mixed by end-to-end inversion and left to incubate at room temperature for $3 \mathrm{~h}$. Following the incubation step, $150 \mu \mathrm{L} 2 \mathrm{mg} / \mathrm{mL}$ FAO was added to the DTSSP functionalised nanostars and left to incubate in the fridge overnight. The following day the samples were centrifuged at $1990 \times \mathrm{g}$ for $40 \mathrm{~min}$ and the pellet was resuspended in $1 \mathrm{~mL}$ deionised water. The centrifugation process was repeated twice removing the excess HEPES and FAO in order to maintain star integrity [38]. Successful functionalisation was confirmed by observing the expected red shift in the UV-Vis spectrum, a decrease cathodal migration with peak broadening during agarose gel electrophoresis and an increase in hydrodynamic diameter as measured by DLS. These criteria for successful functionalisation was previously established in our laboratory along with definitive confirmation by NMR characterisation [37].

\subsection{Feasibility Assay (unattached FAO)}

Assays were carried out in a 96-well plate format. Reagents were added and pipette mixed in the following order: Ultrapure water to a final volume of $200 \mu \mathrm{L}, 20 \mu \mathrm{L} 10 \mathrm{mM}$ TRIS buffer (pH 6.1), 15 $\mu \mathrm{L}$ AuNs, $0-0.03 \mathrm{mM}$ range fructosyl valine (which is a 1:500 dilution of the expected concentration in blood samples (approximately 3-15 mM glycated haemoglobin [8,39]) and $2 \mu \mathrm{L} 2 \mathrm{mg} / \mathrm{mL}$ fructosyl amino acid oxidase. The plate was then incubated on the microplate spectrophotometer for $60 \mathrm{~min}$ at $37^{\circ} \mathrm{C}$ after which the detection solution was added using a multichannel pipette. The detection solution consisted of $2 \mu \mathrm{L} 10 \mathrm{mM}$ silver nitrate followed by $7 \mu \mathrm{L} 500 \mathrm{mM}$ sodium hydroxide. The plate was then left in the spectrophotometer for $5 \mathrm{~min}$ after which the spectra were obtained and the colorimetric result was observed. We have previously shown that AuNs gave a sufficient change in colour based on varying concentrations of neat hydrogen peroxide and that sodium hydroxide was the base to use in the detection solution [37].

\subsection{Stability Assay}

The stability of the FAO-AuNs were assessed with the standard sodium chloride flocculation assay $(300 \mathrm{mM} \mathrm{NaCl})$ and in blank serum. Serum was used to assess the ability of the biosensor in a complex matrix and was considered to be a reasonable proxy for haemolysates. $50 \mu \mathrm{L}$ FAO-AuNs was added to $50 \mu \mathrm{L}$ of $\mathrm{NaCl}$ and serum respectively and were read on the microplate spectrophotometer every $15 \mathrm{~min}$ for $2 \mathrm{~h}$ and again at $18 \mathrm{~h}$. Since the FAO-AuNs is being utilised as a biosensor it is not necessary for the particles to be stable in the serum environment over a long period of time. A 
red UV-Vis spectral shift as well as broadening of the spectral curve were considered indicative of instability or the development of a protein corona [31,40].

\subsection{Specificity Assay}

Non-specific reactions by assay components were tested by omitting individual components in turn and comparing the results to a control containing all components. Fructosyl valine was replaced with $1 \mathrm{mM} \mathrm{L}$-valine. The reagents were added and pipette mixed in the following order: Ultrapure water to a final volume of $200 \mu \mathrm{L}$ including the detection solution, $20 \mu \mathrm{L} 10 \mathrm{mM}$ TRIS buffer (pH 6.1), $15 \mu \mathrm{L}$ FAO-AuNs, $10 \mu \mathrm{L} 1 \mathrm{mM}$ fructosyl valine. Incubation, detection and spectral acquisitions was as described for the fructosyl valine feasibility assay with the exception that the sodium hydroxide volume was increased to $20 \mu \mathrm{L}$. Samples were then transferred to $1.5 \mathrm{~mL}$ microtubes for better colorimetric visualisation.

\subsection{FAO-AuNs Colorimetric Assay}

The colorimetric ability of the FAO-AuNs nanostars were assessed in both water and serum each test was run in triplicate. The use of a complex, protein containing matrix is important as it is known that a protein corona forms around nanostars which can prevent colour development [41]. Both assays were optimised chemometrically. The serum samples were prepared by spiking blank serum with $12 \mathrm{mM}$ fructosyl valine followed by dilution in water to range $0.3-1.5 \mathrm{mM}$. In water a 0.6 to $3 \mathrm{mM}$ range was optimal. The assay procedure was as described for the FAO specificity assay accept for adding $2 \mu \mathrm{L}$ fructosyl valine range of concentrations and $20 \mu \mathrm{L}$ and $25 \mu \mathrm{L} 500 \mathrm{mM}$ sodium hydroxide to the water and serum assay respectively. Results were observed after approximately $10 \mathrm{~min}$ incubation with the detection solution. The final fructosyl valine concentration was a $1000 \times$ dilution of the expected $3 \mathrm{mM}$ to $15 \mathrm{mM} \mathrm{HbA}$ reference range.

\section{Results and Discussion}

The results for the feasibility assay are presented in Figure 2. An increase in the fructosyl valine concentration resulted in the colour of the solution changing from blue, to purple to red and a blue shift (to the left) in the spectral curve. The change in the wavelength at ODmax was linearly correlated with the fructosyl valine concentration over the tested range. This indicated that the FAO reaction produced sufficient hydrogen peroxide in correlation with the concentration of substrate added rendering this a feasible option for $\mathrm{HbA}_{1 \mathrm{c}}$ measurement.

Evidence for successful FAO-AuNs functionalisation is presented in Figure 3. The $12 \mathrm{~nm}$ red shift with peak broadening, the decreased cathodal agarose gel electrophoresis migration pattern and $14.78 \mathrm{~nm}$ increase in the hydrodynamic diameter of the nanostars after functionalisation were consistent with our previous findings on glucose oxidase functionalisation as well as with that shown by $\mathrm{Xi}$ et. al. This is, therefore, indicative of successful functionalisation [37,42]. 


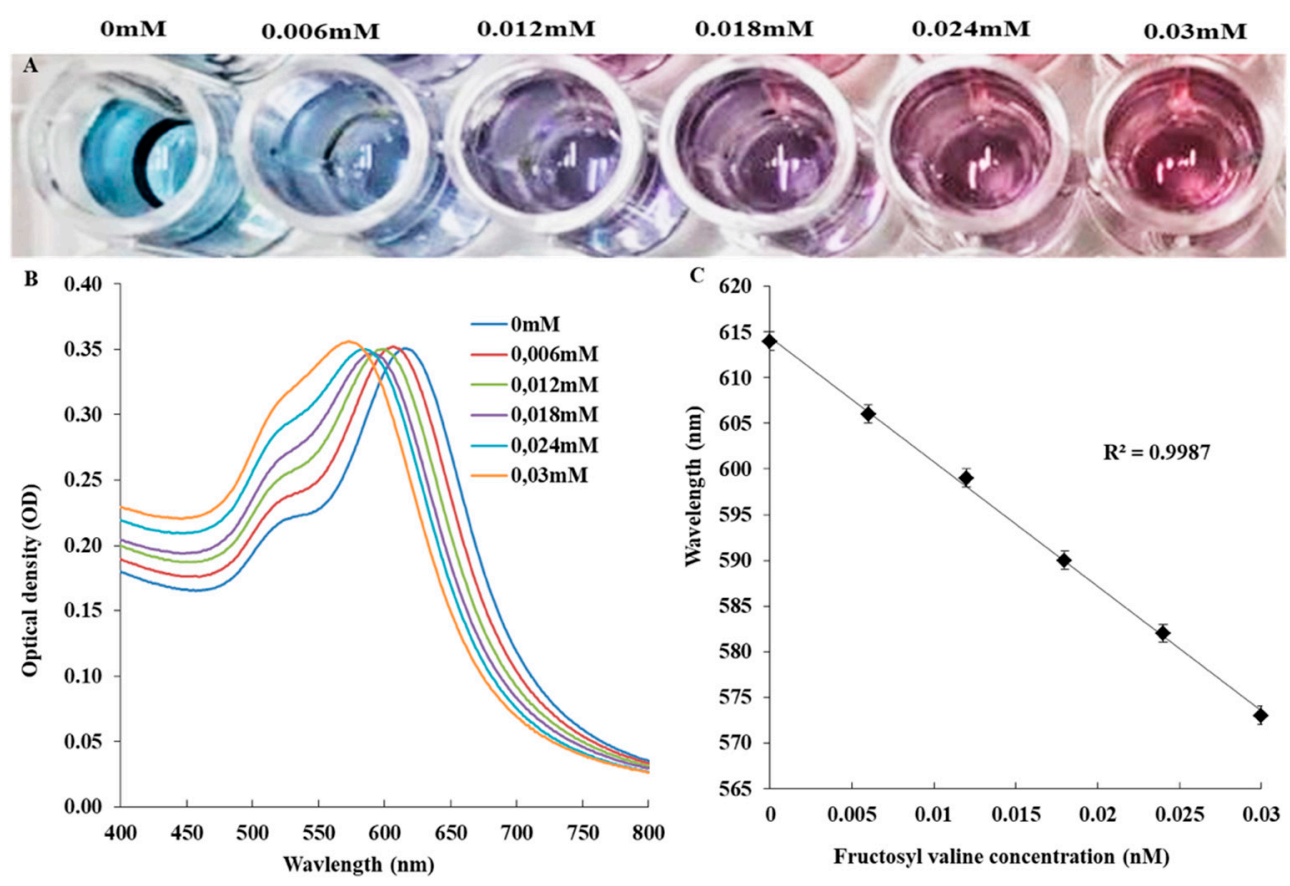

Figure 2. Feasibility assay. (A) Photograph showing the colour change of the nanostar with increased fructosyl valine concentration. (B) The corresponding UV-vis spectra and (C) scatter plot of the wavelength at ODmax and fructosyl valine concentration with linear regression fit.

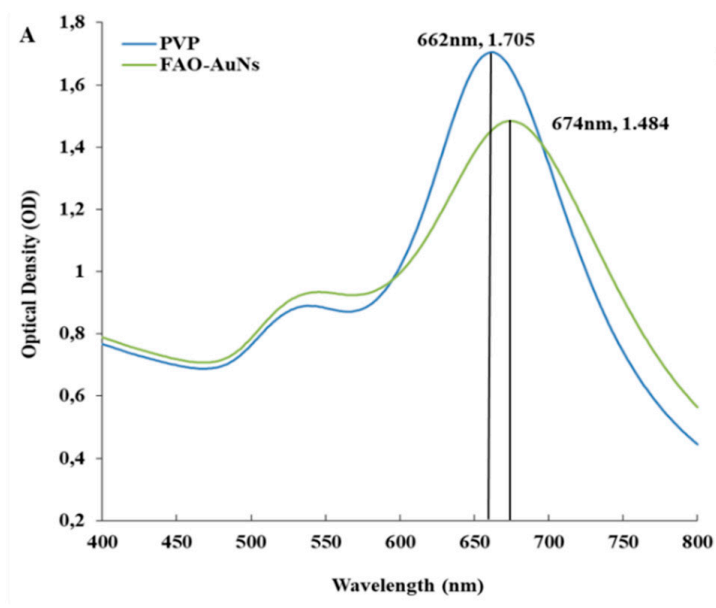

B

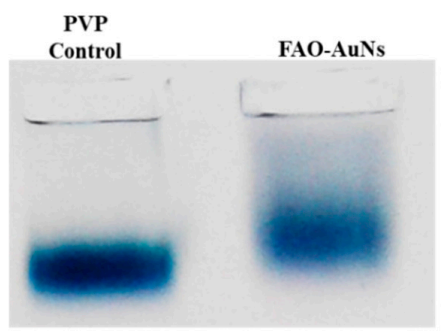

C Table 1: DLS data for PVP control and functionalised nanostars

\begin{tabular}{|c|c|c|c|}
\hline Sample & $\begin{array}{c}\text { Mean } \\
\text { diameter }(\mathrm{nm})\end{array}$ & $\begin{array}{c}\text { Standard } \\
\text { deviation }\end{array}$ & $\begin{array}{c}\text { Polydispersity } \\
\text { index (PDI) }\end{array}$ \\
\hline PVP control & 39.97 & 0.9814 & 0.425 \\
\hline FAO-AuNs & 54.75 & 0.5632 & 0.305 \\
\hline
\end{tabular}

Figure 3. Confirmation of FAO-AuNs functionalisation. (A) UV-Vis spectra, (B) agarose gel electrophoresis and (C) DLS results of functionalised and unfunctionalised nanostars.

The stability assay data is shown in Figure 4. The FAO-AuNs were stable in the serum environment as the initial response of the nanostars resulted in a sudden shift of the spectrum and then maintained the same characteristic as the control over time (Figure 4B). In the salt environment the maximum optical density (OD max) declined by 30\% within the first 30 min with a marginal red shift after which it remained stable for at least up to two hours (Figure 4A). The biosensor did not need to be stable in a complex matrix such as serum for long periods as the result should be obtained in the shortest possible time frame. There was a horizontal relationship between the maximum optical density and time for the serum environments indicating nanostar stability (Figure 4C). The maximum optical density and time for the salt environment showed a decline in relationship for the first $2 \mathrm{~h}$ and then plateaued out until the $18 \mathrm{~h}$ time point (Figure 4D). 

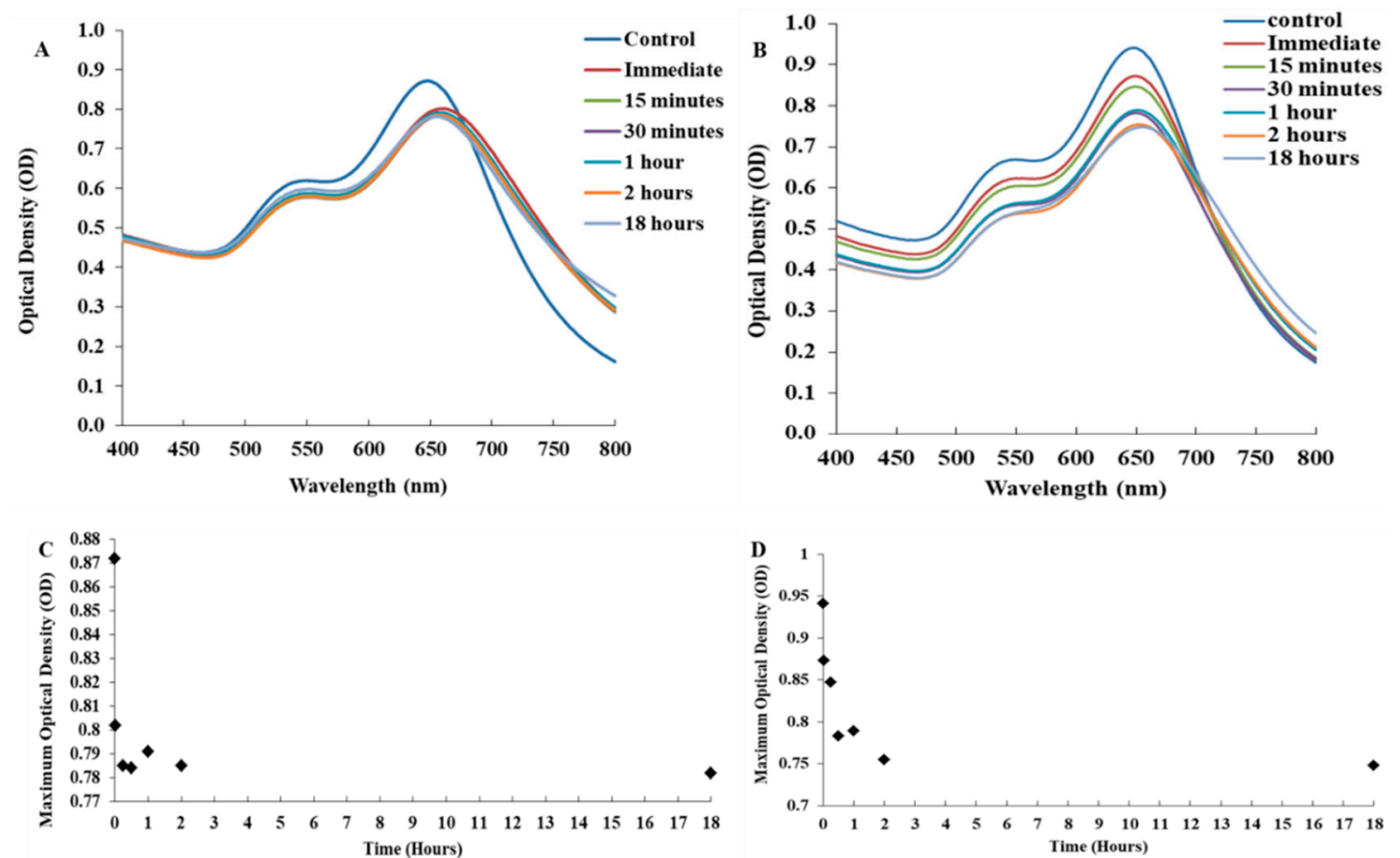

Figure 4. Stability of the FAO-AuNs in serum $(\mathbf{A}, \mathbf{C})$ and salt $(\mathbf{B}, \mathbf{D})$.

Data supporting the specificity of the FAO-AuNs assay is presented in Figure 5. Although marginal shifts did occur with the omission of various reaction components, the magnitude was less than the shift with all components present even without prior optimisation of the reaction conditions. In addition silver reduction without the presence of nanostars did not result in a significant shift.
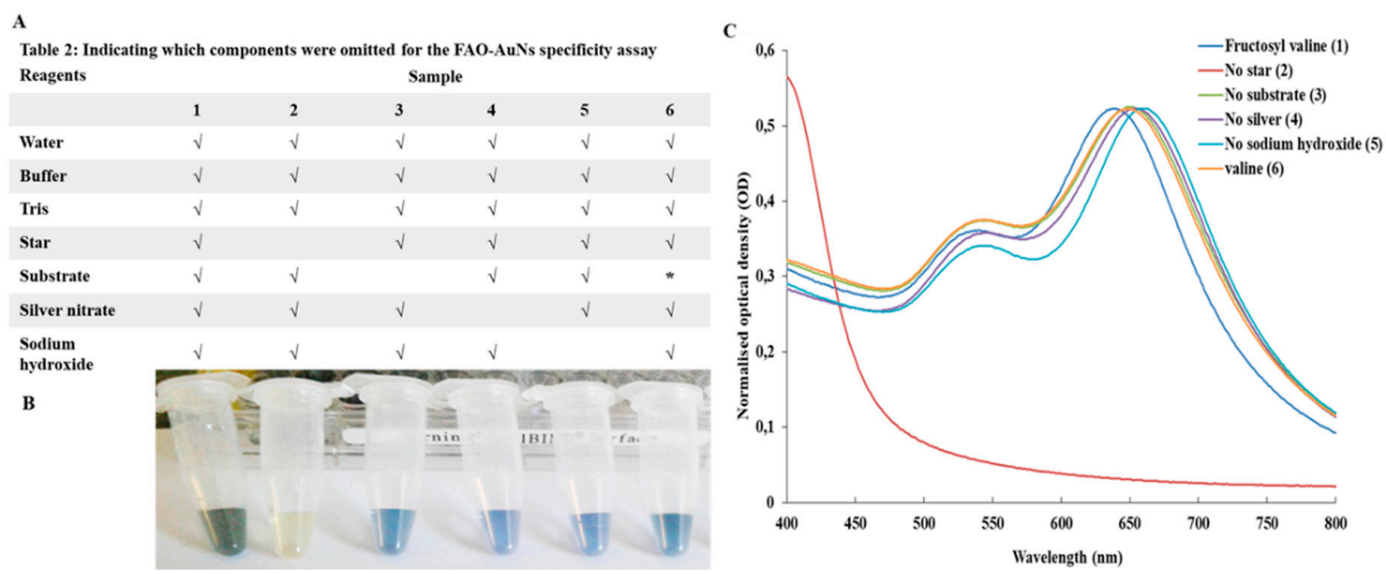

Figure 5. Specificity assay. (A) Table showing omitted reaction components accept for * which indicates the replacement of fructosyl valine with L-valine. (B) Photograph of the colours obtained for the reaction as laid out in the table. (C) Corresponding normalised UV-Vis spectra.

The compound figure in Figure 6, shows the contrast of colour obtained between the water and serum environment as well as the spectral and linearity data. 


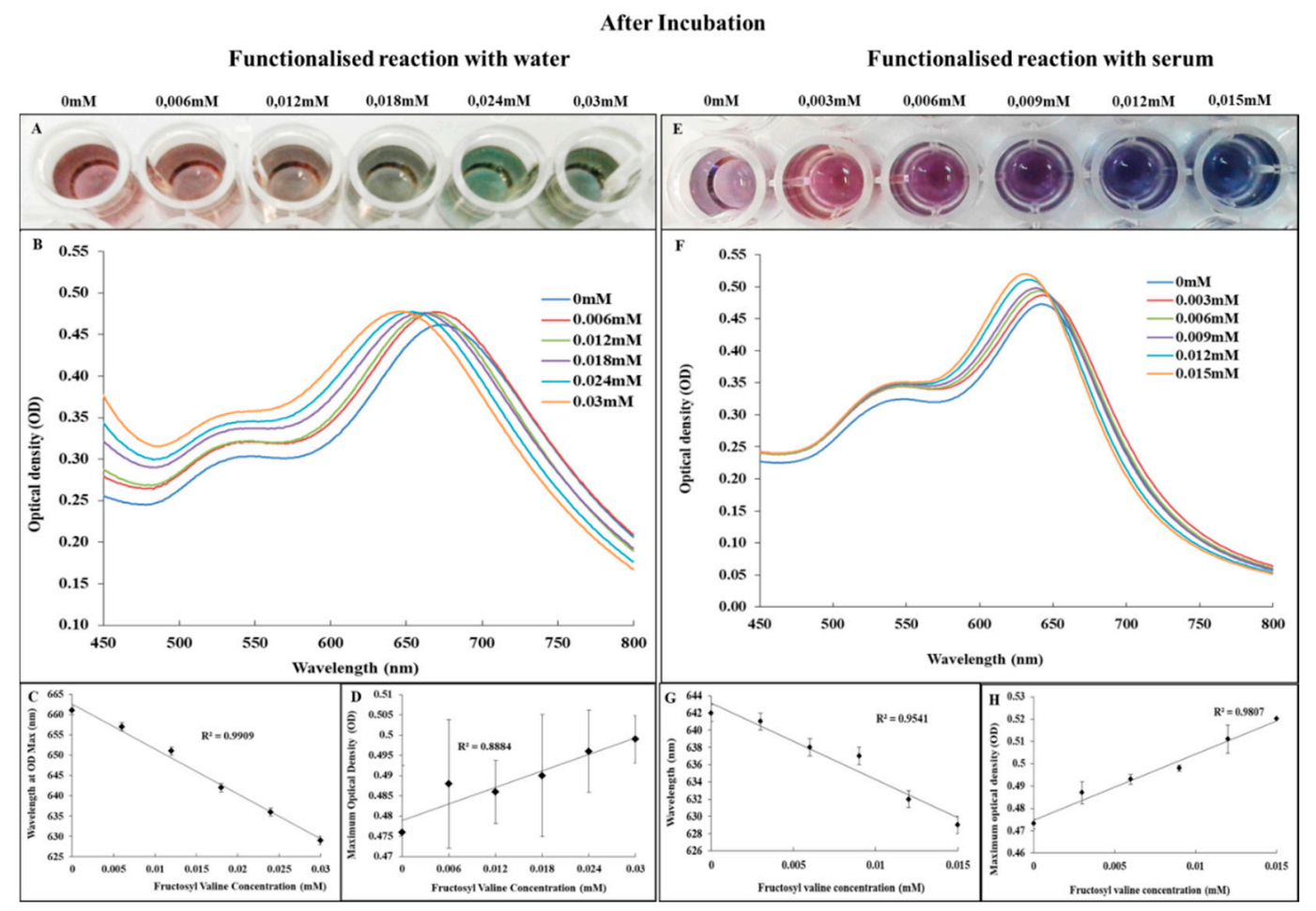

Figure 6. Matrix effects evaluation assays: (A) Photograph showing the colour of the FAO-AuNs in water. (B) UV-Vis spectra for FAO-AuNs in water immediately after detection solution is added. (C,D) Linear relationships for FAO-AuNs (in water) between fructosyl valine concentration and shift in wavelength and maximum optical density respectively. (E) Photograph showing the colour of the FAO-AuNs in serum after incubation. (F) UV-Vis spectra for FAO-AuNs in serum immediately after addition of detection solution. $(\mathbf{G}, \mathbf{H})$ Linear relationships for FAO-AuNs (in serum) between fructosyl valine concentration and wavelength and maximum optical density respectively.

In Figure 6A, it can be seen that the FAO-AuNs solution changed to a colour range of red, orange, yellow and green. The spectral shift in Figure $6 \mathrm{~B}$ was a blue shift with the highest concentration of fructosyl valine blue shifting the most which concurred with Figure 2B. This pattern in spectral shift and constant OD max was described by Zang et.al as a change in morphology by etching and growth while maintaining the nanoparticle size as no change in OD max was noted [30]. This was confirmed by the images in Figure 7B-D. The colour change difference between Figure 6A,E could be attributed to a protein corona which forms around the nanostars changing the nanostar physiochemical properties [41]. The FAO-AuNs in serum (Figure 6F), also showed a blue shift with the highest concentration of fructosyl valine shifting the most albeit with some change in OD max. 


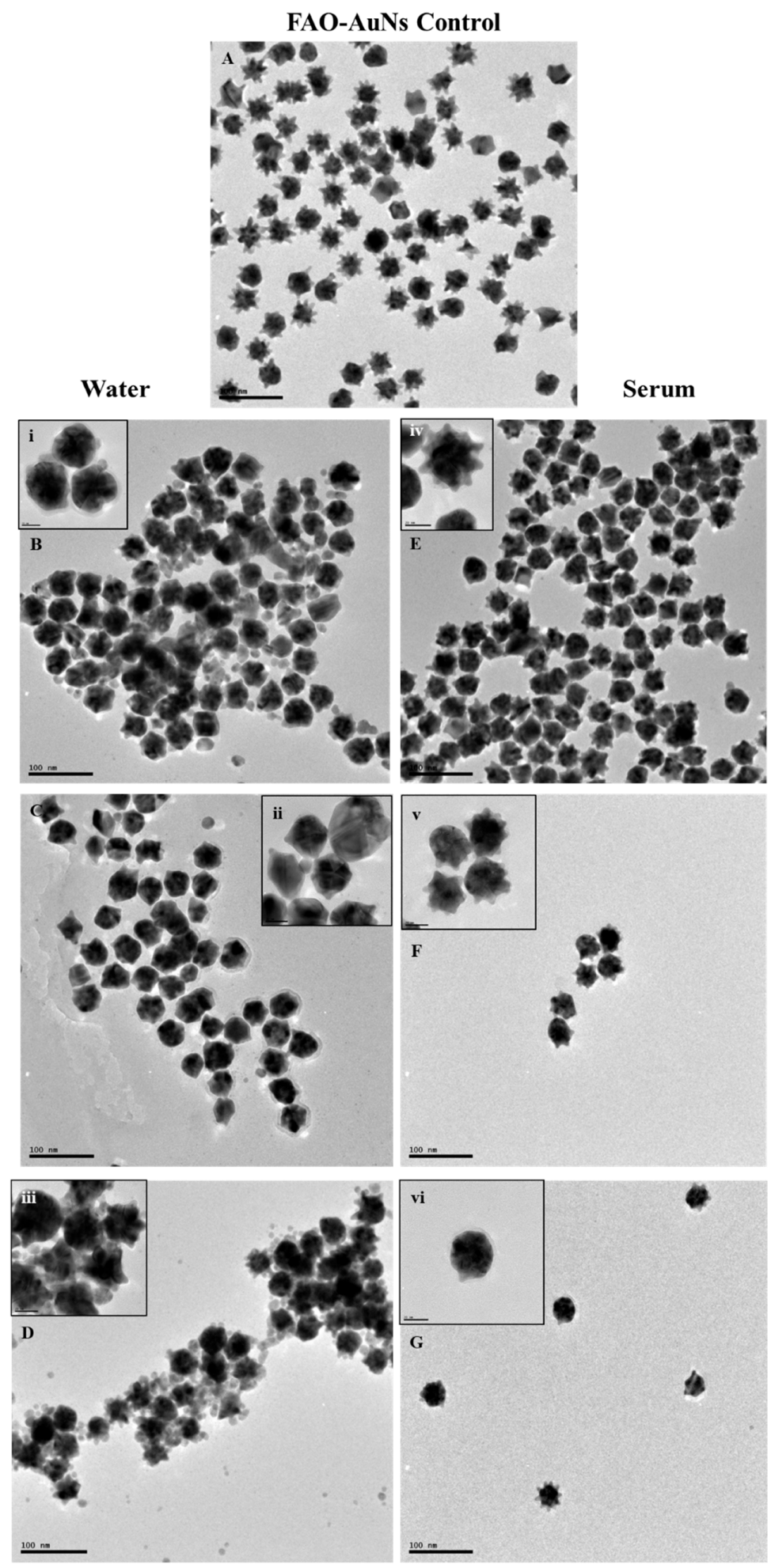

Figure 7. TEM images showing the morphological change of the FAO-AuNs in water and serum for varied fructosyl valine concentrations. (A) Is the morphology of FAO-AuNs after functionalisation. In the water environment (B) $0 \mathrm{mM},(\mathbf{C}) 0.018 \mathrm{mM}$ and (D) $0.03 \mathrm{mM}$. In the serum environment (E) $0 \mathrm{mM}$, (F) $0.009 \mathrm{mM}$ and (G) $0.015 \mathrm{mM}$ respectively. The inserts for each image shows a closer view of the particle morphology. 
The possible mechanism contributing to the colour change was investigated by viewing the particle morphology via TEM. It is proposed that the colour was attributed via enzyme-mediated etching and growth of the gold nanostars [30]. A proposed scheme is illustrated in Figure 8 [43].

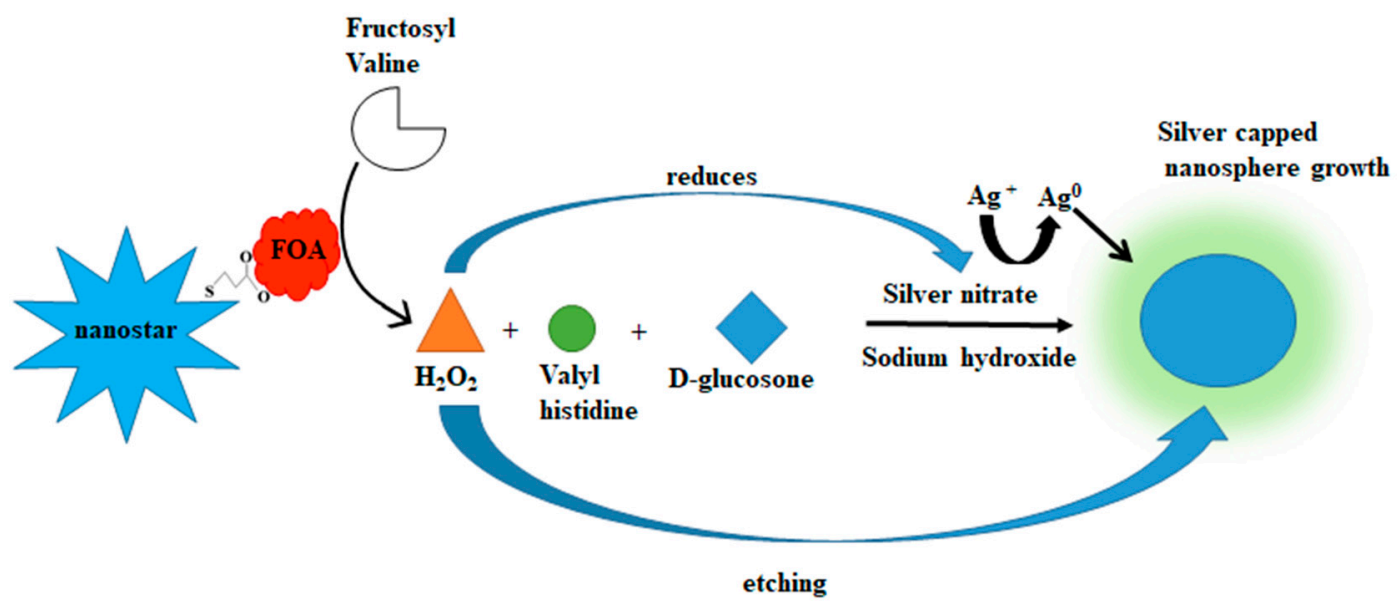

Figure 8. Proposed reaction scheme for the colorimetric reaction obtained by the FAO-AuNs in serum.

The TEM images of the nanoparticles in both the water and serum are shown in Figure 7 below.

When the nanostar was functionalized, the shape of the nanostar was maintained as seen in the TEM image in Figure 7A. The TEM images seen in Figure 7E-G support Figure 8. The morphology change of the FAO-AuNs in serum as seen in Figure 7E-G resulted in the shortening of the FAO-AuNs arms compared with the functionalisation control (7A). The arms were gradually removed until finally resulting in more spherical nanoparticles. The etching and growth of the FAO-AuNs in water followed a different pattern where the shape started off more spherical and as the substrate concentration increased the shape became more polyhedral in nature with a final poly-morphological sample coated by silver nanoparticles [37].

As seen in Figures 6 and 7, the biosensor was able to detect low levels of fructosyl valine which was via the etching and growth of the gold nanostar. The combination of the TEM images and the colorimetric data gave an indication to the mechanism attributing to the colour change. This gives a better understanding of how these particular nanostars react in a complex matrix such a serum which will assist with optimisation when applying these biosensors to blood.

\section{Conclusions}

It was previously shown that using silver as a shape directing agent in a HEPES seedless synthesis method that more homogenous gold nanostars with multiple branches were produced [36]. These nanostars were functionalised with glucose oxidase as a model enzyme which showed to be a promising biosensor scaffold for the detection of hydrogen peroxide generated by an enzyme-substrate reaction [37]. This model was then generalised to another hydrogen producing enzyme such as fructosyl valine for $\mathrm{HbA}_{1 \mathrm{c}}$ determination. When compared to traditional chromatogens, functionalised FAO-AuNs offered the advantage of colorimetric naked eye and spectrophotometric detection by using smaller sample volumes which are desirable for POC applications. For potential future application, the quantification of the colour changes obtained could possibly be done via smartphone apps or an external mobile add-on [44-47]. The biosensor was also stable in a complex matrix such as serum. Future work in our laboratory will, therefore, be in optimising the blood sample preparation by cleaving the glycated valine from haemoglobin with limited reagents as to limit interference for the colorimetric assay platform which was established in this study. The future work will also include validation using patient samples and comparing it to the traditional enzyme method for which ethics will be required. 
Author Contributions: D.W.M. conceived the study, designed the study, carried out the laboratory work, participated in data analysis and drafted the manuscript. B.C.V. and M.M.P. participated in design of the study, data analysis and drafting of the manuscript. All authors gave their approval for publication.

Funding: We would also like to thank the North-West University's Centre of Human Metabolomics (CHM) and the South African Technology Innovation Agency (TIA) for the funding given in order to carry out this work.

Acknowledgments: We would like to acknowledge Innocent Shuro from the Laboratory for Electron Microscopy, Chemical Resource Beneficiation, North-West University, Potchefstroom, South Africa, for assistance with obtaining the nanoparticle images.

Conflicts of Interest: There is no conflict of interest to report.

\section{References}

1. World Health Organization. Global Report on Diabetes; World Health Organization: Albany, NY, USA, 2016; p. 86.

2. Adepoyibi, T.; Weigl, B.; Greb, H.; Neogi, T.; McGuire, H. New screening technologies for type 2 diabetes mellitus appropriate for use in tuberculosis patients. Public Health Action 2013, 3, S10-S17. [CrossRef] [PubMed]

3. Weigl, B.H.; Drake, J.K. Developing an Adaptable Set of Point-of-Care Diabetes Screening Technologies for Low-Resource Settings. Point Care 2013, 12, 33-40. [CrossRef]

4. David, B.S. Chapter 57: Diabetes Mellitus. In Tietz Textbook of Clinical Chem. and Molecular Diagnostics, 6th ed.; Rifai, N., Horvath, A.R., Wittwer, C.T., Eds.; Elsevier: St. Louis, Missouri, MO, USA, 2018; p. 1888.

5. Cavero-Redondo, I.; Peleteiro, B.; Álvarez-Bueno, C.; Rodríguez-Artalejo, F.; Martínez-Vizcaíno, V. Glycosylated haemoglobin as a predictor of cardiovascular events and mortality: A protocol for a systematic review and meta-analysis. BMJ Open 2016, 6, e012229. [CrossRef] [PubMed]

6. Rifai, N.; Horvath, A.R.; Wittwer, C. Tietz Textbook of Clinical Chemistry and Molecular Diagnostics, 6th ed.; Elsevier: Amsterdam, The Netherlands, 2018; p. 1867.

7. Camargo, J.L.; Gross, J.L. Conditions associated with very low values of glycohaemoglobin measured by an HPLC method. J. Clin. Pathol. 2004, 57, 346-349. [CrossRef] [PubMed]

8. Gupta, S.; Jain, U.; Chauhan, N. Laboratory Diagnosis of HbA1c: A Review. J. Nanomed. Res. 2017, 5, 00120.

9. Hamwi, A.; Schweiger, C.R.; Veitl, M.; Schmid, R. Quantitative measurement of HbA1c by an immunoturbidimetric assay compared to a standard HPLC method. Am. J. Clin. Pathol. 1995, 104, 89-95. [CrossRef] [PubMed]

10. Jaisson, S.; Desmons, A.; Renard, B.; Chevelle, B.; Leroy, N.; Gillery, P. Analytical performances of a new enzymatic assay for hemoglobin A1c. Clin. Chim. Acta Int. J. Clin. Chem. 2014, 434, 48-52. [CrossRef] [PubMed]

11. Liu, L.; Hood, S.; Wang, Y.; Bezverkov, R.; Dou, C.; Datta, A.; Yuan, C. Direct enzymatic assay for \%HbA1c in human whole blood samples. Clin. Biochem. 2008, 41, 576-583. [CrossRef]

12. Owen, M. The glucose vs. HbA1c controversy. Clinicians weigh arguments for both types of diabetes testing. MLO. Méd. Lab. Obs. 2015, 47, 26-27.

13. Chang, K.W.; Li, J.; Yang, C.H.; Shiesh, S.C.; Lee, G.B. An integrated microfluidic system for measurement of glycated hemoglobin Levels by using an aptamer-antibody assay on magnetic beads. Biosens. Bioelectron. 2015, 68, 397-403. [CrossRef]

14. Chawla, S.; Pundir, C.S. An electrochemical biosensor for fructosyl valine for glycosylated hemoglobin detection based on core-shell magnetic bionanoparticles modified gold electrode. Biosens. Bioelectron. 2011, 26, 3438-3443. [CrossRef] [PubMed]

15. Liu, A. A New Electrochemical HbA1c Biosensor Based on Flow Injection and Screen-Printed Electrode. Int. J. Electrochem. Sci. 2016, 11, 3086-3094. [CrossRef]

16. Olyaee, S.; Seifouri, M.; Mohsenirad, H. Label-free detection of glycated haemoglobin in human blood using silicon-based photonic crystal nanocavity biosensor. J. Mod. Opt. 2016, 63, 1274-1279. [CrossRef]

17. Chien, H.-C.; Chou, T.C. A Nonenzymatic Amperometric Method for Fructosyl-Valine Sensing Using Ferroceneboronic Acid. Electroanalysis 2011, 23, 402-408. [CrossRef] 
18. Ferri, S.; Kim, S.; Tsugawa, W.; Sode, K. Review of fructosyl amino acid oxidase engineering research: A glimpse into the future of hemoglobin A1c biosensing. J. Diabetes Sci. Technol. 2009, 3, 585-592. [CrossRef] [PubMed]

19. Jain, U.; Singh, A.; Kuchhal, N.K.; Chauhan, N. Glycated hemoglobin biosensing integration formed on Au nanoparticle-dotted tubular $\mathrm{TiO}_{2}$ nanoarray. Anal. Chim. Acta 2016, 945, 67-74. [CrossRef] [PubMed]

20. Syedmoradi, L.; Daneshpour, M.; Alvandipour, M.; Gomez, F.A.; Hajghassem, H.; Omidfar, K. Point of care testing: The impact of nanotechnology. Biosens. Bioelectron. 2017, 87, 373-387. [CrossRef] [PubMed]

21. Liu, Z.; Zhao, F.; Gao, S.; Shao, J.; Chang, H. The Applications of Gold Nanoparticle-Initialed Chemiluminescence in Biomedical Detection. Nanoscale Res. Lett. 2016, 11, 460. [CrossRef] [PubMed]

22. Posthuma-Trumpie, G.A.; Korf, J.; van Amerongen, A. Lateral flow (immuno)assay: Its strengths, weaknesses, opportunities and threats. A literature survey. Anal. Bioanal. Chem. 2009, 393, 569-582. [CrossRef]

23. Saha, K.; Agasti, S.S.; Kim, C.; Li, X.; Rotello, V.M. Gold Nanoparticles in Chemical and Biological Sensing. Chem. Rev. 2012, 112, 2739-2779. [CrossRef]

24. Ding, S.; Cargill, A.A.; Medintz, I.L.; Claussen, J.C. Increasing the activity of immobilized enzymes with nanoparticle conjugation. Curr. Opin. Biotechnol. 2015, 34, 242-250. [CrossRef] [PubMed]

25. Guo, L.; Jackman, J.A.; Yang, H.-H.; Chen, P.; Cho, N.-J.; Kim, D.-H. Strategies for enhancing the sensitivity of plasmonic nanosensors. Nano Today 2015, 10, 213-239. [CrossRef]

26. Atta, S.; Tsoulos, T.V.; Fabris, L. Shaping Gold Nanostar Electric Fields for Surface-Enhanced Raman Spectroscopy Enhancement via Silica Coating and Selective Etching. J. Phys. Chem. C 2016, 120, 20749-20758. [CrossRef]

27. Lee, K.-S.; El-Sayed, M.A. Dependence of the Enhanced Optical Scattering Efficiency Relative to That of Absorption for Gold Metal Nanorods on Aspect Ratio, Size, End-Cap Shape, and Medium Refractive Index. J. Phys. Chem. B 2005, 109, 20331-20338. [CrossRef] [PubMed]

28. Tang, L.; Li, J. Plasmon-Based Colorimetric Nanosensors for Ultrasensitive Molecular Diagnostics. ACS Sens. 2017, 2, 857-875. [CrossRef] [PubMed]

29. Webb, J.A.; Erwin, W.R.; Zarick, H.F.; Aufrecht, J.; Manning, H.W.; Lang, M.J.; Pint, C.L.; Bardhan, R. Geometry-Dependent Plasmonic Tunability and Photothermal Characteristics of Multibranched Gold Nanoantennas. J. Phys. Chem. C 2014, 118, 3696-3707. [CrossRef]

30. Zhang, Z.; Wang, H.; Chen, Z.; Wang, X.; Choo, J.; Chen, L. Plasmonic colorimetric sensors based on etching and growth of noble metal nanoparticles: Strategies and applications. Biosens. Bioelectron. 2018, 114, 52-65. [CrossRef]

31. Rodríguez-Lorenzo, L.; de la Rica, R.; Álvarez-Puebla, R.A.; Liz-Marzán, L.M.; Stevens, M.M. Plasmonic nanosensors with inverse sensitivity by means of enzyme-guided crystal growth. Nat. Mater. 2012, 11, 604. [CrossRef]

32. Lim, S.A.; Ahmed, M.U. Electrochemical immunosensors and their recent nanomaterial-based signal amplification strategies: A review. RSC Adv. 2016, 6, 24995-25014. [CrossRef]

33. Brar, S.K.; Verma, M. Measurement of nanoparticles by light-scattering techniques. Trends Anal. Chem. 2011, 30, 4-17. [CrossRef]

34. Pecora, R. Dynamic Light Scattering Measurement of Nanometer Particles in Liquids. J. Nanopart. Res. 2000, 2, 123-131. [CrossRef]

35. De Puig, H.; Tam, J.O.; Yen, C.W.; Gehrke, L.; Hamad-Schifferli, K. Extinction Coefficient of Gold Nanostars. J. Phys. Chem. C Nanomater. Interfaces 2015, 119, 17408-17415. [CrossRef] [PubMed]

36. Mulder, D.W.; Phiri, M.M.; Vorster, B.C. Modified HEPES One-Pot Synthetic Strategy for Gold Nanostars. R. Soc. Open Sci. 2019, 6, 190160. [CrossRef] [PubMed]

37. Mulder, D.W.; Phiri, M.M.; Vorster, B.C. Tailor-made gold nanostar colorimetric detection determined by morphology change and used as an indirect approach by using hydrogen peroxide to determine glucose concentration. Sens. Bio-Sens. Res. 2019, in press. [CrossRef]

38. Xi, W.; Haes, A.J. Elucidation of HEPES Affinity to and Structure on Gold Nanostars. J. Am. Chem. Soc. 2019, 141, 4034-4042. [CrossRef] [PubMed]

39. Sherwani, S.I.; Khan, H.A.; Ekhzaimy, A.; Masood, A.; Sakharkar, M.K. Significance of HbA1c Test in Diagnosis and Prognosis of Diabetic Patients. Biomark. Insights 2016, 11, 95-104. [CrossRef] [PubMed] 
40. Sapsford, K.E.; Algar, W.R.; Berti, L.; Gemmill, K.B.; Casey, B.J.; Oh, E.; Stewart, M.H.; Medintz, I.L. Functionalizing Nanoparticles with Biological Molecules: Developing Chemistries that Facilitate Nanotechnology. Chem. Rev. 2013, 113, 1904-2074. [CrossRef] [PubMed]

41. Aldewachi, H.; Chalati, T.; Woodroofe, M.N.; Bricklebank, N.; Sharrack, B.; Gardiner, P. Gold nanoparticle-based colorimetric biosensors. Nanoscale 2018, 10, 18-33. [CrossRef] [PubMed]

42. Xi, W.; Phan, H.T.; Haes, A.J. How to accurately predict solution-phase gold nanostar stability. Anal. Bioanal. Chem. 2018, 410, 6113-6123. [CrossRef] [PubMed]

43. Xia, Y.; Ye, J.; Tan, K.; Wang, J.; Yang, G. Colorimetric Visualization of Glucose at the Submicromole Level in Serum by a Homogenous Silver Nanoprism-Glucose Oxidase System. Anal. Chem. 2013, 85, 6241-6247. [CrossRef] [PubMed]

44. Geng, Z.; Zhang, X.; Fan, Z.; Lv, X.; Su, Y.; Chen, H. Recent Progress in Optical Biosensors Based on Smartphone Platforms. Sensors 2017, 17, 2499. [CrossRef] [PubMed]

45. Huang, X.; Xu, D.; Chen, J.; Liu, J.; Li, Y.; Song, J.; Ma, X.; Guo, J. Smartphone-based analytical biosensors. Analyst 2018, 143, 5339-5351. [CrossRef] [PubMed]

46. Rateni, G.; Dario, P.; Cavallo, F. Smartphone-Based Food Diagnostic Technologies: A Review. Sensors 2017, 17, 1453. [CrossRef] [PubMed]

47. Sun, A.C.; Yao, C.; Venkatesh, A.G.; Hall, D.A. An Efficient Power Harvesting Mobile Phone-Based Electrochemical Biosensor for Point-of-Care Health Monitoring. Sens. Actuators B Chem. 2016, 235, 126-135. [CrossRef] [PubMed]

(C) 2019 by the authors. Licensee MDPI, Basel, Switzerland. This article is an open access article distributed under the terms and conditions of the Creative Commons Attribution (CC BY) license (http://creativecommons.org/licenses/by/4.0/). 